\title{
Normalization of Serum Alkaline Phosphatase in Primary Sclerosing Cholangitis Associated with Ulcerative Colitis
}

\author{
Mitsuro Chiba ${ }^{*}$, Hidehiko Tsuda ${ }^{2}$, Satoko Tsuda ${ }^{1}$, Masafumi Komatsu$^{1}$, Yasuo Horie ${ }^{3}$, \\ Hirohide Ohnishi ${ }^{3}$ \\ ${ }^{1}$ Division of Gastroenterology, Akita City Hospital, Akita, Japan \\ ${ }^{2}$ Division of Gastroenterology, Akita Kumiai General Hospital, Akita, Japan \\ ${ }^{3}$ Depatment of Gastroenterology, Akita University School of Medicine, Akita, Japan \\ Email: ${ }^{*}$ acd00517@akita-city-hp.jp
}

Received 22 February 2014; revised 27 March 2014; accepted 6 April 2014

Copyright (C) 2014 by authors and Scientific Research Publishing Inc.

This work is licensed under the Creative Commons Attribution International License (CC BY). http://creativecommons.org/licenses/by/4.0/

\section{Open Access}

\begin{abstract}
Primary sclerosing cholangitis (PSC) is commonly associated with ulcerative colitis (UC). PSC progresses independently of UC ultimately resulting in liver failure. There is no established medical treatment to improve the natural course of PSC. Normalization of serum alkaline phosphatase (ALP) in early stage might delay the progress of PSC. A 20-year-old female, had a sudden attack of right hypochondralgia with high fever and abnormal liver function tests without elevation of bilirubin: ALP $478 \mathrm{IU} / \mathrm{L}$, aspartate aminotransferase $360 \mathrm{IU} / \mathrm{L}$, alanine aminotransferase $174 \mathrm{IU} / \mathrm{L}$. Abnormal liver function tests returned to normal after the attacks. Morphological examinations initially indicated then confirmed a diagnosis of PSC. One month after displaying PSC symptoms administration of ursodeoxycholic acid was initiated. Similar attacks of cholangitis were repeated several times over the following two years. Even in the absence of these attacks, she always suffered postprandial hypochondralgia. There was no acute cholangitis in the year prior to the last hospitalization due to abdominal pain and bloody diarrhea. Findings were consistent with UC in the form of entire colitis. Sulfasalazine, metronidazole and semi-vegetarian diet (SVD) were initiated. Metronidazole is routinely used in inflammatory bowel disease (IBD) in our practice with the expectation of elimination of any potentially pathogenic bacteria. SVD was designed for IBD hoping to increase beneficial bacteria. A remission of UC was ascertained during hospitalization. Elevated ALP, in the absence of clinical cholangitis, was decreased to normal after the therapy for UC.
\end{abstract}

*Corresponding author. 


\title{
Keywords
}

\author{
Primary Sclerosing Cholangitis, Ulcerative Colitis, Alkaline Phosphatase, Metronidazole, \\ Vegetarian Diet
}

\section{Introduction}

Primary sclerosing cholangitis (PSC) is a progressive disease resulting in liver cirrhosis followed by liver failure with a median survival of approximately 17 years after diagnosis [1]. Inflammatory bowel disease (IBD), particularly ulcerative colitis (UC) is strongly associated with PSC: approximately at $80 \%$ of PSC in western countries and at 35\% in Asia [2]. There has been no medical therapy to alter natural course of PSC except for liver transplantation which is indicated at a late stage of the disease. Ursodeoxycholic acid (UDCA) decreases serum alkaline phosphatase (ALP) without clinical benefit [3]. High-dose UDCA rather increases risk of adverse outcomes [4]. Therefore, medical treatment of PSC has been eagerly awaited. Unknown etiology, the lack of an adequate animal model and the relative infrequency of the disease remain major obstacles to progress [2]. Recently normalization of ALP is shown to be associated with better prognosis in PSC [1]. In such circumstances a recent pilot study demonstrated the efficacy of antibiotics, both vancomycin and metronidazole, in decreasing serum ALP in PSC [5]. This study was designed on the concept that bacterially derived molecules from the gut showing dysbiosis is critical in the development of PSC (PSC microbiota hypothesis) [2]. Vancomycin and metronidazole were used to restore gut dysbiosis [5].

Gut dysbiosis is observed in IBD in both UC and Crohn's disease [6]. The main cause of the dysbiosis is diet in the developed countries, namely westernized diet [7]. Therefore, a semi-vegetarian diet has been designed hoping to increase beneficial bacteria [8]. Metronidazole is routinely used in active IBD, in our practice, expecting an elimination of any potentially pathogenic bacteria [8]. Our current practice in IBD is also aiming at restoring gut dysbiosis [7] [8]. We experienced a case with PSC in which ALP was normalized by an induction therapy for the first attack of associated UC.

\section{Case Report}

A 20-year-old female (weight $38 \mathrm{~kg}$ ), in November 2009, had a sudden attack of right hypochondralgia with high fever and abnormal liver function tests without elevation of bilirubin: ALP 478 IU/L (normal range 101 340), aspartate aminotransferase (AST) $360 \mathrm{IU} / \mathrm{L}$ (7 - 30), alanine aminotransferase (ALT) 174 IU/L (0 - 32) (Table 1). On the following day, symptoms rapidly ameliorated with rapid improvement in liver function tests: ALP 326, AST 68, and ALT 103. Her past history was noncontributory. Morphological studies including abdominal ultrasonography, computed tomography and magnetic resonance cholangiopancreatography were not diagnostic. A similar episode recurred a week later. Endoscopic retrograde cholangiopancreatography (ERCP) was performed. Neither biliary stone nor abnormal pancreatobiliary junction was found. Only a part of peripheral ducts could be opacified. Cholangiogram showed unevenness of caliber indicating stricture of hepatic bile duct (Figure 1(A)). Therefore, PSC was strongly suspected. UDCA, $600 \mathrm{mg} /$ day was initiated. Colonoscopy on December 2009 ruled out an association of UC. Since March 2011, she often suffered postprandial right hypochondralgia and it occurred more often in May 2011. During that time she had an attack of cholangitis: right hypochondralgia and high fever. In addition to an elevation of ALP, AST and ALT, leucocytosis $\left(13,200 / \mathrm{mm}^{3}\right)$ was found. Antibiotic was effective in ameliorating the symptoms. ERCP showed a progression of intrahepatic and extrahepatic biliary strictures confirming a diagnosis of PSC (Figure 1(B)). There was a flow of pus by sphincterotomy. A plastic stent, $5 \mathrm{~cm}$ of 8.5 French in diameter was temporarily placed [9]. Similar attacks of purulent cholangitis were repeated four times over the following five months. Stent placement, $10 \mathrm{~cm}$ of 8.5 French in the right hepatic duct for 12 days was ineffective in reducing postprandial hypochondralgia. Flopropione (Cospanon ${ }^{\circledR}$, Eisai, Tokyo), $120 \mathrm{mg} /$ day, was initiated in September 2011. There was no acute cholangitis after October 2011. Even in the absence of the attack, postprandial right hypochondralgia persisted. Therefore, she took jelly with very small amounts of ordinary meals and took an analgesic on a daily basis. Diarrhea temporally appeared in August 2012 when she was 23-year-old. Sigmoidoscopy in September 2012 showed a vascular pattern with scattered redness. In November 2012, she was admitted due to abdominal pain and frequent 
Table 1. Laboratory data.

\begin{tabular}{|c|c|c|c|c|c|c|c|c|c|}
\hline Item & & $\begin{array}{l}\text { (Normal } \\
\text { range) }\end{array}$ & $\begin{array}{l}\text { Nov } 2009 \\
\text { on attack }\end{array}$ & $\begin{array}{l}\text { Nov } 2012 \\
\text { on } \\
\text { admission }\end{array}$ & Item & & $\begin{array}{l}\text { (Normal } \\
\text { range) }\end{array}$ & $\begin{array}{l}\text { Nov } 2009 \\
\text { on attack }\end{array}$ & $\begin{array}{c}\text { Nov } 2012 \\
\text { on } \\
\text { admission }\end{array}$ \\
\hline Total protein & (g/dL) & $(6.7-8.2)$ & 7.0 & 8.3 & $\begin{array}{l}\text { Anti-mitochondrial } \\
\mathrm{Ab}\end{array}$ & & (Negative) & Negative & \\
\hline Albumin & (g/dL) & $(3.8-5.2)$ & & 4.0 & $\begin{array}{c}\text { Anti-smooth muscle } \\
\text { Ab }\end{array}$ & & (Negative) & Negative & \\
\hline$\alpha_{2}$ globulin & (\%) & $(4.8-8.6)$ & & 8.6 & Anti-nuclear Ab & & $<40 \times$ & $160 \times$ & $80 x$ \\
\hline Total bilirubin & (mg/dL) & $(0.2-1.2)$ & 0.8 & 0.6 & & & & $\begin{array}{r}\text { Homoge } \\
\text { spec }\end{array}$ & $\begin{array}{l}\text { eneous \& } \\
\text { ckled }\end{array}$ \\
\hline $\begin{array}{l}\text { Alkaline } \\
\text { phosphatase }\end{array}$ & (IU/L) & $(101-340)$ & 478 & 758 & Rheumatoid factor & & $0-10$ & 0 & \\
\hline AST & $(\mathrm{IU} / \mathrm{L})$ & $(7-30)$ & 360 & 34 & P-ANCA & & $<3.5$ & 21 & \\
\hline ALT & (IU/L) & $(0-32)$ & 174 & 23 & $\begin{array}{l}\text { Anti-ribonucler } \\
\text { protein } \mathrm{Ab}\end{array}$ & & (Negative) & Negative & \\
\hline $\begin{array}{c}\text { Lactate } \\
\text { dehydrogenase }\end{array}$ & (IU/L) & $(101-230)$ & 328 & 221 & IgG & $(\mathrm{mg} / \mathrm{dL})$ & $(700-2000)$ & 1653 & 2271 \\
\hline Total cholesterol & (mg/dL) & $(110-220)$ & 122 & 104 & IgG4 & $(\mathrm{mg} / \mathrm{dL})$ & $(4.8-105.0)$ & 10.5 & \\
\hline $\begin{array}{l}\text { Blood urea } \\
\text { nitrogen }\end{array}$ & $(\mathrm{mg} / \mathrm{dL})$ & $(7-20)$ & 9.6 & 4.7 & IgA & $(\mathrm{mg} / \mathrm{dL})$ & $(94-365)$ & 124 & 141 \\
\hline Creatinine & $(\mathrm{mg} / \mathrm{dL})$ & $(0.4-1.1)$ & 0.5 & 0.5 & $\operatorname{Ig} M$ & $(\mathrm{mg} / \mathrm{dL})$ & $(30-120)$ & 84 & 93 \\
\hline $\begin{array}{l}\text { C-reactive } \\
\text { protein }\end{array}$ & $(\mathrm{mg} / \mathrm{dL})$ & $(\leq 0.3)$ & 0.4 & 1.3 & $\operatorname{IgE}$ & $(\mathrm{IU} / \mathrm{mL})$ & $(<173)$ & & 533 \\
\hline ESR & $(\mathrm{mm} / \mathrm{hr})$ & $(<15)$ & & 68 & Stool culture & & Negative & & Negative \\
\hline Blood sugar & $(\mathrm{mg} / \mathrm{dL})$ & $(60-120)$ & 113 & 106 & CMV antigenemia & & 0 & & 0 \\
\hline Hemoglobin & $(\mathrm{mg} / \mathrm{dL})$ & $(12.0-15.1)$ & 13.1 & 12.1 & Anti-CMV Ab IgM & & $<0.80$ & 0.31 & 0.58 \\
\hline White blood cell & $\left(/ \mathrm{mm}^{3}\right)$ & $(3900-8800)$ & 15,300 & 6200 & Anti-CMV Ab IgG & & $<2.0$ & 2.0 & $<2.0$ \\
\hline Platelet & $\left(\times 10^{4} / \mathrm{mm}^{3}\right)$ & $(15.2-31.4)$ & 21.7 & 38.4 & EBV VCA IgG & & $<10$ & 640 & \\
\hline $\begin{array}{l}\text { Hepatitis B } \\
\text { surface Ag }\end{array}$ & & Negative & Negative & & EBV VCA IgM & & $<10$ & $<10$ & \\
\hline $\begin{array}{l}\text { Hepatitis } \mathrm{C} \text { virus } \\
\mathrm{Ab}\end{array}$ & & Negative & Negative & & EBNA & & $<10$ & $<10$ & \\
\hline $\begin{array}{c}\text { IgM Hepatitis A } \\
\mathrm{Ab}\end{array}$ & & Negative & Negative & & HLA-DR & & & & DR 15 \\
\hline
\end{tabular}

AST, asparate aminotransferase; ALT, alanine aminotransferase; ESR, erythrocyte sedimentation rate; Ag, antigen; Ab, antibody; P-ANCA, perinuclear antineutrophil cytoplasmic antibody; CMV, cytomegalovirus; EBV, Epstein-Barr virus; VCA, viral capsid antigen; EBNA, Epstein-Barr virus antibody to nuclear antigen; HLA, human leucocyte antigen.

diarrhea mixed with blood. Colonoscopic (Figure 2) and histological findings were consistent with UC in the form of entire colitis. Therapy for UC was initiated: sulfasalazine, metronidazole and semi-vegetarian diet (Figure 3). Clinical and morphological remission was ascertained during hospitalization. In the absence of cholangitis there was an increase of ALP (758 IU/L) (Table 1) which was gradually decreased to normal after the therapy for UC (Figure 3).

\section{Discussion}

There are various peculiar features unsolved in PSC [2]. Albeit the strong association of UC in PSC, activity of both diseases is generally considered to be independent. PSC precedes UC in some case and vice verse in some case. In some case, PSC appears after therapeutic proctocolectomy for UC [2]. In the present case PSC preceded UC. ALP was increased along with attacks of cholangitis and swift normalization after the attacks. However, ALP was increased in the absence of the attacks when she manifested symptoms of UC.

Gradual decreasing of ALP occurred in the present case after commencement of therapy for UC: sulfasalazine, metronidazole and SVD. ALP finally normalized in five months. Metronidazole is effective in reducing ALP 

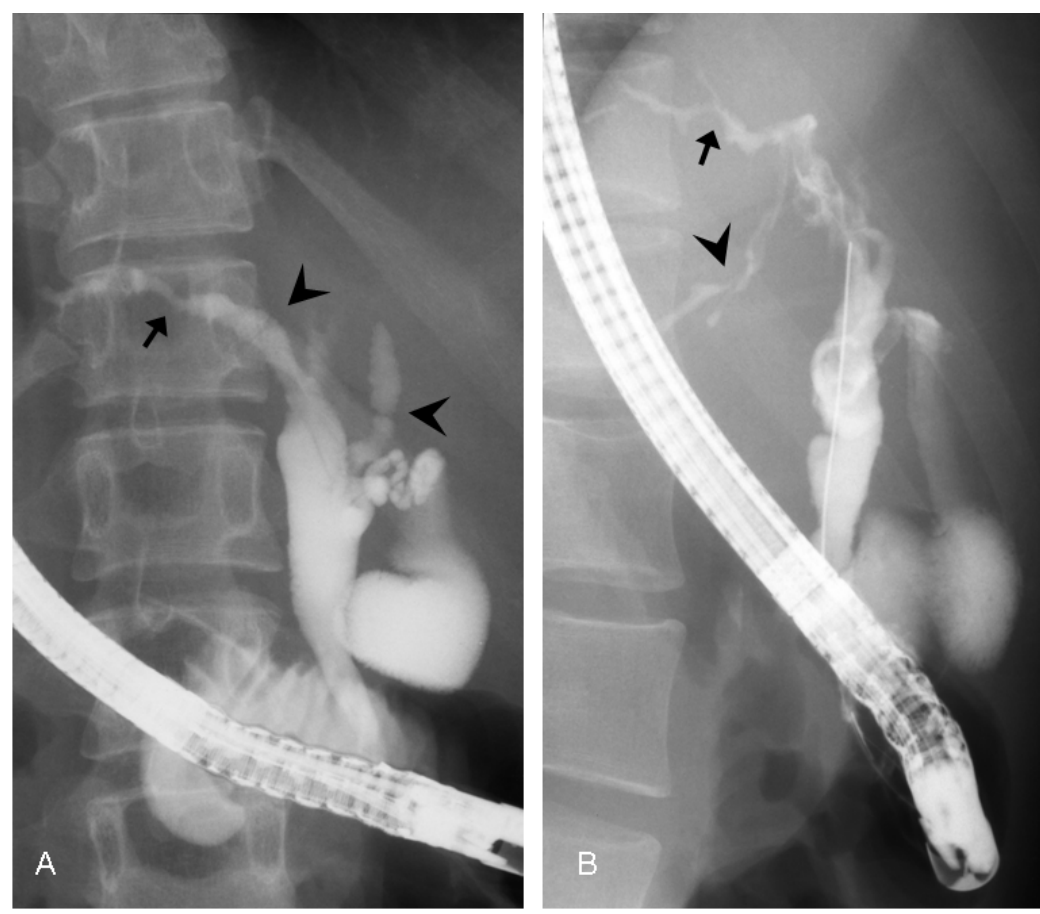

Figure 1. Cholangiogram of bile ducts by endoscopic retrograde cholangiopancreatography in prone position in November 2009 (A) and May 2011 (B). Only a part of the peripheral ducts could be opcified on both occasions. There is an apparent stricture (arrow), webs (arrowheads) and unevenness of caliber indicating primary sclerosing cholangitis (PSC) (A). There is a progression of stricture of bile ducts including the site of arrow (B). Another apparent stricture (arrowhead) is seen (B). These intrahepatic and extrahepatic strictures confirmed the diagnosis of PSC.

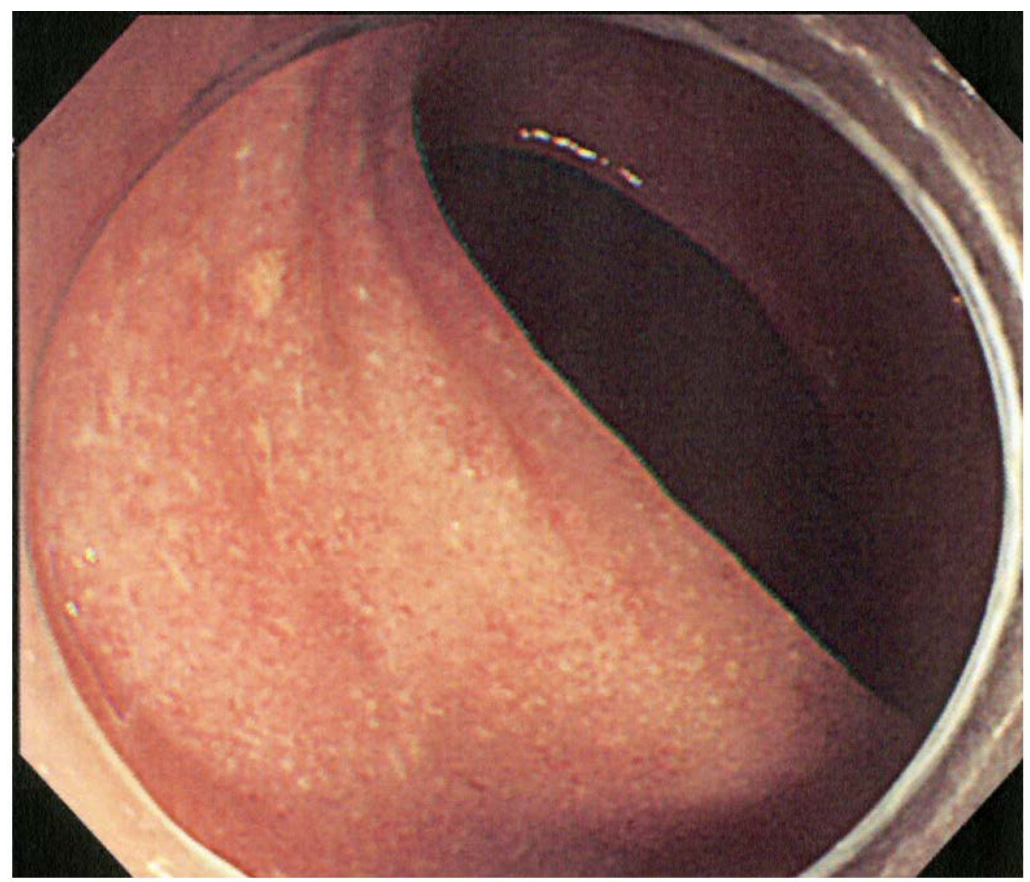

Figure 2. Colonoscopic picture. Colonoscopy soon after admission in November 2012 showed diffuse inflammation. No vascular pattern is observed. 


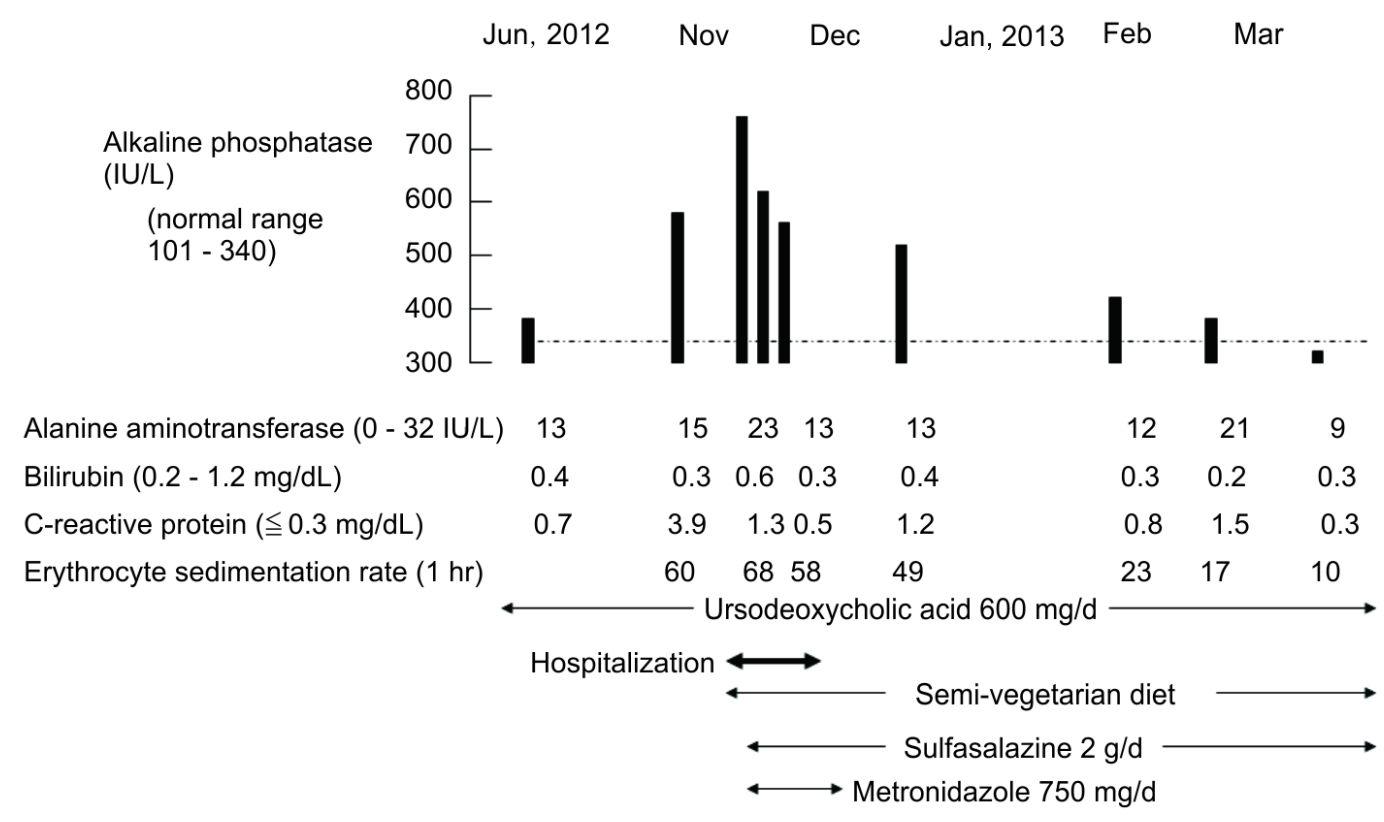

Figure 3. Medication and the change in blood tests including alkaline phosphatase (ALP) around her hospitalization for the first attack of ulcerative colitis. ALP (758 IU/L) (Table 1) which was gradually decreased to normal after the therapy for ulcerative colitis.

[5]. Tada et al. reported that sulfasalazine was effective for PSC associated with UC [10]. We do not know to what extent each of the three modalities contributed to ALP normalization. Considering the variety in natural course [2] and fluctuation in ALP in PSC another possibility of spontaneous normalization of ALP [1] cannot be totally excluded. Although the disease activity of PSC generally does not correlate with the activity of UC [2], in the present case, postprandial right hypochondralgia ameliorated to some extent along with induction of remission in UC. Therefore, there is a possibility that remission induction of UC contributed most to ALP normalization. Tada et al.'s observation [10], improvement of PSC by sulfasalazine, also can be explained by the induction of remission in UC by sulfasalazine. Recently, Duca et al. reported a case in which infliximab induced a favorable course for 2 years in both UC and PSC [11].

We need more experience to determine the role of these three factors mentioned above in normalization of ALP and to understand the significance of the fluctuation of ALP in PSC.

\section{References}

[1] Stanich, P.P., Bjornsson, E., Gossard, A.A., Enders, F., Jorgensen, R. and Lindor, K.D. (2011) Alkaline Phosphatase Normalization Is Associated with Better Prognosis in Primary Sclerosing Cholangitis. Digestve and Liver Disease, 43, 309-313. http://dx.doi.org/10.1016/j.dld.2010.12.008

[2] Aron, J.H. and Bowlus, C.L. (2009) The Immunobiology of Primary Sclerosing Cholangitis. Seminars in Immunopathology, 31, 383-397. http://dx.doi.org/10.1007/s00281-009-0154-7

[3] Triantos, C.K., Koukias, N.M., Nikolopoulou, V.N. and Burroughs, A.K. (2011) Meta-Analysis: Ursodeoxycholic Acid for Primary Sclerosing Cholangitis. Alimentary Pharmacology \& Therapeutics, 34, 901-910. http://dx.doi.org/10.1111/j.1365-2036.2011.04822.x

[4] Imam, M.H., Sinakos, E., Gossard, A.A., et al. (2011) High-Dose Ursodeoxycholic Acid Increases Risk of Adverse Outcomes in Patients with Early Stage Primary Sclerosing Cholangitis. Alimentary Pharmacology \& Therapeutics, 34, 1185-1192. http://dx.doi.org/10.1111/j.1365-2036.2011.04863.x

[5] Tabibian, J.H., Weeding, E., Jorgensen, R.A., et al. (2013) Randomised Clinical Trial: Vancomycin or Metronidazole in Patients with Primary Sclerosing Cholangitis-A Pilot Study. Alimentary Pharmacology \& Therapeutics, 37, 604612. http://dx.doi.org/10.1111/apt.12232

[6] Sartor, R.B. (2004) Therapeutic Manipulation of the Enteric Microflora in Inflammatory Bowel Diseases: Antibiotics, Probiotics, and Prebiotics. Gastroenterology, 126, 1620-1633. http://dx.doi.org/10.1053/j.gastro.2004.03.024

[7] Chiba, M., Tsuda, H., Abe, T., Sugawara, T. and Morikawa, Y. (2011) Missing Environmental Factor in Inflammatory 
Bowel Disease: Diet-Associated Gut Microflora. Inflammatory Bowel Diseases, 17, E82-E83. http://dx.doi.org/10.1002/ibd.21745

[8] Chiba, M., Abe, T., Tsuda, H., et al. (2010) Lifestyle-Related Disease in Crohn's Disease: Relapse Prevention by a Semi-Vegetarian Diet. World Journal of Gastroenterology, 16, 2484-2495. http://dx.doi.org/10.3748/wjg.v16.i20.2484

[9] van Milligen de Wit, A.W., van Bracht, J., Rauws, E.A., Jones, E.A., Tytgat, G.N. and Huibregtse, K. (1996) Endoscopic Stent Therapy for Dominant Extrahepatic Bile Duct Strictures in Primary Sclerosing Cholangitis. Gastrointestinal Endoscopy, 44, 293-299. http://dx.doi.org/10.1016/S0016-5107(96)70167-0

[10] Tada, S., Ebinuma, H., Saito, H. and Hibi, T. (2006) Therapeutic Benefit of Sulfasalazine for Patients with Primary Sclerosing Cholangitis. Journal of Gastroenterology, 41, 388-392. http://dx.doi.org/10.1007/s00535-005-1758-x

[11] Duca, I., Ramirez de la Piscina, P., Estrada, S., et al. (2013) Steroid-Refractory Ulcerative Colitis and Associated Primary Sclerosing Cholangitis Treated with Infliximab. World Journal of Gastroenterology, 19, 590-593. http://dx.doi.org/10.3748/wjg.v19.i4.590

\section{List of Abbreviations}

PSC: primary sclerosing cholangitis

ALP: alkaline phosphatase

SVD: semi-vegetarian diet

IBD: inflammatory bowel disease

UC: ulcerative colitis

UDCA: ursodeoxycholic acid

AST: aspartate aminotransferase

ALT: alanine aminotransferase

ERCP: endoscopic retrograde cholangiopancreatography 